\title{
PREVENTION OF HARM \\ TO CHILDREN'S HEALTH AND DEVELOPMENT \\ BY INFORMATION DISTRIBUTED DURING PAID QUEST ENTERTAINMENT ${ }^{1}$
}

\author{
Evgeniya A. Serbina \\ Volgograd State University, Volgograd, Russian Federation
}

\begin{abstract}
Introduction: the present study shows a high degree of significance of the factor of information and psychological security of minors participating in quests, which is currently at a low level. The purpose of the study is to identify the main guidelines for improving the legal implementation in the field of the quest industry in terms of evolution of the law enforcement in the context of introducing the innovative management technologies. Methods: the methodological framework for the research is presented as general scientific methods, including dialectical, inductive, deductive, analytical, statistical methods, interviewing and questioning, as well as specific scientific methods, such as the formal legal method, the method of legal interpretation, the principle of evaluating legal processes, etc. Results: the paper considers the initiatives of the National Quest Association (NQA) on the criteria for setting the age limits for quests. The problems of practical implementation of restricting access of minors to information dangerous for their mental health and development are noted. Conclusions: it is proved that there is a need to strengthen the external industry control in the field of protecting children from information that harms their health and development, as well as to improve the administrative legislation in this area.

Key words: information and psychological security, protection of children from harmful information, quest rooms, quest industry, Russian Age Raiting System.

Citation. Serbina E.A. Prevention of Harm to Children's Health and Development by Information Distributed During Paid Quest Entertainment. Legal Concept, 2020, vol. 19, no. 3, pp. 97-102. (in Russian). DOI: https:// doi.org/10.15688/lc.jvolsu.2020.3.13
\end{abstract}

УДК 342.9

Дата поступления статьи: 27.06.2020

ББК 67.401 .122 Дата принятия статьи: 15.07.2020

\section{ПРЕВЕНЦИЯ ПРИЧИНЕНИЯ ВРЕДА ЗДОРОВЬЮ И РАЗВИТИЮ ДЕТЕЙ ИНФОРМАЦИЕЙ, РАСПРОСТРАНЯЕМОЙ ПРИ ОСУЩЕСТВЛЕНИИ ВОЗМЕЗДНЫХ КВЕСТ-РАЗВЛЕЧЕНИЙ ${ }^{1}$}

\author{
Евгения Александровна Сербина \\ Волгоградский государственный университет, г. Волгоград, Российская Федерация
}


ния, принцип оценки правовых процессов и др. Результаты: рассмотрены инициативы Национальной ассоциации участников квест-индустрии (НАУК) о критериях установления возрастных ограничений квестов. Отмечаются проблемы практической реализации ограничения доступа несовершеннолетних к опасной для психического здоровья и развития информации. Выводы: доказана необходимость усиления внешнего отраслевого контроля в области защиты детей от информации, причиняющей вред их здоровью и развитию, а также совершенствования административного законодательства в указанной сфере.

Ключевые слова: информационно-психологическая безопасность, защита детей от вредной информации, квест-комнаты, квест-индустрия, возрастная классификация информационной продукции.

Цитирование. Сербина Е. А. Превенция причинения вреда здоровью и развитию детей информацией, распространяемой при осуществлении возмездных квест-развлечений // Legal Concept = Правовая парадигма.-2020. - Т. 19, № 3. -C. 97-102. -DOI: https://doi.org/10.15688/lc.jvolsu.2020.3.13

\section{Введение}

Понятие «информационно-психологическая безопасность» было введено в научный оборот в 1996 г. в связи с усилением роли информации в жизни общества и в настоящий момент прочно устоялось в доктрине [8]. Информационно-психологический аспект безопасности личности в эпоху внедрения инновационных технологий в общественную жизнь приобретает особую важность. Неоиндустриальные преобразования привели к существенному росту объемов информации и скорости ее распространения. В этих условиях ограничение доступа к информации, способной причинить вред здоровью лиц с подвижной психикой, многократно затрудняется [5].

Заботясь о психологическом благополучии несовершеннолетних, государство разрабатывает различные меры обеспечения информационно-психологической безопасности детей. Одна из них - Федеральный закон от 29 декабря 2010 г. № 436-Ф3 «О защите детей от информации, причиняющей вред их здоровью и развитию» (далее по тексту - Ф3). На развлекательные игры в формате квестов требования ФЗ также распространяются.

В настоящее время контроль за соблюдением указанных требований законодательства носит бессистемный, эпизодический характер. Это происходит прежде всего потому, что установление возрастных ограничений на игры в формате квестов возложено на их организаторов в соответствии с ч. 1 ст. 6 Ф3. При этом на уровне саморегулирования отрасли квест-индустрии контроль соблюдения требований возрастных ограничений не осуществляется должным образом. В связи с этим допуск к играм, демонстрирующим в натуралистическом виде сцены жестокости, насилия, последствия убийств, получают лица, не обладающие должным уровнем психологической устойчивости в связи с недостижением соответствующего возраста. Так, в ходе опроса сотрудников квест-комнат установлено, что к прохождению квестов формата «контактный перформанс» компании «Квест-Хилл» в жанре хоррор допускались несовершеннолетние в возрасте от 13 лет. При этом актеры получали дополнительные инструкции в отношении несовершеннолетних, а именно: для подростков в возрасте от 13 до 16 лет не применяются шокеры, роль актера уменьшается, снижается уровень контакта.

Сайт-агрегатор www.volgograd.mirkvestov.ru указал возрастное ограничение для квестов, организуемых компанией «Clever», для лиц старше 12 лет [2]. При этом в эскейпкомнате под названием «Логово» присутствовали такие устрашающие элементы, как натуралистические муляжи окровавленных конечностей, манекены, изображающие трупов, один из которых заперт внутри клетки, а другой «распят» на фоне черного гроба, висящего на стене, следы краски, имитирующие кровоподтеки на стенах и хирургических инструментах, что явным образом демонстрирует информацию, вызывающую у детей страх, ужас или панику, в виде изображения последствий насильственной смерти [4].

Таким образом, организаторы квестов по-разному оценивают правовые нормы, касающиеся законодательства о защите детей от информации, причиняющей вред их здоровью и развитию, и дифференцированно подходят к установлению возрастных ограничений в отношении организуемых ими квестов. 


\section{Факторы, повышающие уровень информационно-психологической \\ безопасности несовершеннолетних участников квестов}

В качестве одного из факторов, который может способствовать снижению рисков вредоносного влияния на физическое и нравственное состояние несовершеннолетних при прохождении квестов, на наш взгляд, следует рассматривать установление единообразных критериев оценки сценария, обстановки и актерского перформанса на предмет информационно-психологической безопасности для несовершеннолетних.

Стандарт безопасности услуг в квестиндустрии, разработанный уже не действующей в настоящее время Национальной ассоциацией участников квест-индустрии, предусмотрел ряд требований, касающихся возрастных ограничений. По нашему мнению, основные положения этого акта могут представлять научный интерес в целях совершенствования законодательства в сфере информационно-психологической безопасности. Так, п. 4 Стандарта указал в качестве средства снижения риска психофизиологической опасности строгое соблюдение возрастного ценза в соответствии с ФЗ. Однако конкретный возраст должен устанавливаться организатором самостоятельно (данный вывод следует из п. 1 Приложения 1). Единственной специальной рекомендацией НАУК является то, что посещение контактных перформансов не рекомендуется для лиц, не достигших 18 лет [6].

На наш взгляд, связывать возрастные ограничения с фактором наличия контакта с актером во время игры не совсем верно, поскольку минимальный контакт с актером, предусматривающий легкие прикосновения и ведение от точки к точке в случае, если жанр квеста не предполагает устрашений, не способен нанести вред здоровью и психическому развитию несовершеннолетнего. Более того, квесты, организуемые для несовершеннолетних младшего и среднего школьного возраста, в принципе небезопасны, если в помещении квест-комнаты отсутствует взрослый. С другой стороны, даже эскейп-рум без какого-либо взаимодействия с актерами может быть оборудован сверхреалистичным устрашающим реквизитом.

По нашему мнению, прямая связь возрастного ограничения должна прослеживаться с жанром квеста. Так, квесты в жанре хоррор в зависимости от уровня контакта и актерского перформанса могут допускать участие лиц, достигших 16 или 18 лет.

На наш взгляд, закрепление указанных ограничений в тексте стандарта безопасности, разработанного саморегулируемой организацией, и возложение контрольных полномочий на специализированный экспертный совет при СРО позволит существенно снизить риск нарушений требований законодательства о защите детей от информации, причиняющей вред их здоровью и нормальному развитию.

Однако само по себе установление возрастных ограничений не принесет должного эффекта без соответствующих гарантий при реализации нормативных ограничений. Даже с учетом установленных организатором возрастных ограничений, соответствующих уровню угрозы психическому состоянию несовершеннолетних в процессе игры, на практике очень часто происходит нарушение указанных ограничений.

Опрос, проведенный среди лиц, посещавших квесты, показал, что лишь в 35,9 \% случаев допуск к игре осуществлялся на основании документа, удостоверяющего личность. 16,7 \% респондентов указали, что возраст участников устанавливался посредством устного опроса, почти $40 \%$ опрошенных ответили, что возраст организаторы устанавливали, руководствуясь внешними признаками. Эти же сведения подтверждаются результатами опроса актеров и администраторов квест-комнат ${ }^{2}$.

Судебная практика также свидетельствует о привлечении к административной ответственности организаторов квест-комнат, которые ненадлежащим образом исполняют требования законодательства о защите детей от информации, причиняющей вред их здоровью и развитию $[1 ; 3 ; 4]$.

В связи с вышеизложенным, на наш взгляд, необходимо установить обязанность для администраторов квестов удостоверяться в достижении игроками возраста, установленного ограничением, посредством истребования документа, удостоверяющего личность, 
у всех игроков команды. Контроль за исполнением указанного требования необходимо возложить на комиссию при СРО.

Еще одним открытым вопросом в сфере защиты детей от информации, причиняющей вред их здоровью и развитию, является указание организаторами квеста на необходимость присутствия родителей (законных представителей) несовершеннолетнего игрока в случае, если последний не достиг возраста, установленного ограничением.

В соответствии с ч. 5 ст. 11 Ф3 в присутствии родителей или иных законных представителей детей, достигших возраста 6 лет, допускается оборот информационной продукции для детей, достигших возраста 12 лет. Иных указаний на допуск детей и подростков с согласия родителей к информации, не предназначенной для несовершеннолетних, в законодательстве не содержится.

Экстраполяция указанного положения на иные возрастные ограничения в практике встречается достаточно часто. Например, для квестов «Инферно» установлено возрастное ограничение «для лиц старше 18 лет», но при этом, по заверению актера, участие в квестах принимали также несовершеннолетние в возрасте 14-17 лет с обязательным участием родителей. Однако такая экстраполяция едва ли может считаться правомерной.

Около $20 \%$ опрошенных игроков сталкивались с ситуациями, когда для участия в квесте несовершеннолетнего игрока требовалось сопровождение законного представителя. Однако условие организатора квеста об участии законного представителя несовершеннолетнего продиктовано требованиями законодательства, связанными с ответственностью за жизнь и здоровье ребенка внутри локации, а также с частичной либо неполной дееспособностью несовершеннолетнего в части заключения сделок и гражданско-правовой ответственности по деликтным обязательствам.

Исходя из вышеизложенного, участие законного представителя в квесте вместе с несовершеннолетним не влечет за собой отмену или снижение возрастных ограничений для ребенка, поскольку требования ФЗ носят императивный характер и не отдаются на усмотрение лиц, ответственных за воспитание несовершеннолетнего. Присутствие законного представителя должно являться безусловным фактором при заключении договора об оказании развлекательной услуги квест-комнаты с участием игрока, обладающего неполной дееспособностью (не достигшего возраста 14 лет).

\section{Заключение}

Подводя итог, необходимо отметить высокую степень значимости фактора информационно-психологической безопасности несовершеннолетних [8] участников квеста, обеспечение которой в настоящее время находится на низком уровне вследствие того, что современное действующее законодательство не адаптировано к специфике квест-индустрии и не учитывает ряд ее особенностей.

Повышенный уровень психоэмоционального воздействия квестов на несовершеннолетних участников детерминирует необходимость установления единой системы критериев возрастных ограничений. Предлагаемый Национальной ассоциацией участников квест-индустрии подход, ставящий возраст участников в зависимость от наличия контакта между игроком и аниматором, концептуально не верен. По нашему мнению, возраст участников необходимо ставить в зависимость от жанра квеста.

Повышенное внимание следует уделить также проблемам реализации возрастных ограничений в практике, поскольку в настоящее время даже действующие ограничения, принятые организатором, не соблюдаются в угоду увеличения числа клиентов и, соответственно, прибыли.

Одним из наиболее часто встречающихся в практике нарушений является допуск к участию в квестах несовершеннолетних лиц, не достигших возраста, установленного организатором, в случае, если этих лиц сопровождают законные представители. Подобные допущения нуждаются в искоренении, поскольку противоречат действующему законодательству.

В связи с вышеизложенным необходим внешний контроль за исполнением законодательства в сфере защиты детей от информации, причиняющей вред их здоровью и разви- 
тию. По нашему мнению, государственные инструменты, задействованные в осуществлении контрольных мероприятий, необходимо дополнить отраслевым контролем, а именно создать экспертную комиссию при саморегулируемой организации, в обязанности которой будут вменены соответствующие полномочия.

\section{ПРИМЕЧАНИЯ}

${ }^{1}$ Исследование выполнено за счет гранта Российского научного фонда (проект № 20-18-00314).

The work was supported by Russian Science Foundation (project no. 20-18-00314).

2 Эмпирический материал при проведении исследования получен посредством анкетирования и интервьюирования фокус-групп, в состав которых вошли потребители развлекательных услуг квест-комнат, а также их сотрудники. Персональные данные изъяты.

\section{СПИСОК ЛИТЕРАТУРЫ}

1. Головко, И. И. Типичные нарушения законодательства о защите несовершеннолетних от вредоносной информации / И. И. Головко, Д. С. Солодянкина // Ученые записки Крымского федерального университета имени В.И. Вернадского. Юридические науки. - 2017. - Т. 3 (69), № 2. - С. 88-96.

2. Квест в реальности «Логово» в Волгограде от «Clever». - Электрон. текстовые дан. - Режим доступа: https://volgograd.mir-kvestov.ru/quests/cleverlogovo (дата обращения: 25.06.2020). - Загл. с экрана.

3. Постановление суда Октябрьского района г. Саратова от 09.01.2017 № 5-5/2017. 1 // Судебные и нормативные акты РФ. - Электрон. текстовые дан. Режим доступа: https://sudact.ru/regular/doc/ Phu33ItbgXN5 (дата обращения: 25.06.2020). - Загл. с экрана.

4. Постановление Центрального районного суда г. Волгограда от 15.01.2020 по делу № 5-32/ 2020 // Судебные и нормативные акты РФ. - Электрон. текстовые дан. - Режим доступа: https:// sudact.ru/regular/doc/VZxpHg6MZaZf (дата обращения: 25.06.2020). - Загл. с экрана.

5. Пояснительная записка к проекту Федерального закона «О защите детей от информационной продукции, причиняющей вред их здоровью, нравственному и духовному развитию». - Электрон. текстовые дан. - Режим доступа: https://www.oprf.ru/ru/ about/structure/structurenews/newsitem/13977? PHPSESSID=bqcq8r4p0882 tdmo6iaonb6eb1 (дата обращения: 05.03.2020). - Загл. с экрана.
6. Стандарт безопасности. Услуги в квестиндустрии. Рекомендованные требования по обеспечению безопасности клиентов (игроков) квесткомпаний. - Электрон. текстовые дан. - Режим доступа: https://www. ассоциацияквестовроссии.рф/ standart-bezopasnosti-v-kvestindust (дата обращения: 29.02.2020). - Загл. с экрана.

7. Федеральный закон от 29.12.2010 № 436-Ф3 «О защите детей от информации, причиняющей вред их здоровью и развитию» // Российская газета. -2010 . - 31 дек. (№ 297).

8. Юшина, О. Л. Публичная библиотека в обеспечении информационно-психологической безопасности читателей : дис. ... канд. пед. наук : 05.25.03 / Юшина Ольга Леонидовна. - СПб., 2005. - 237 с.

\section{REFERENCES}

1. Golovko I.I., Solodyankina D.S. Tipichnye narusheniya zakonodatelstva o zashchite nesovershennoletnikh ot vredonosnoy informatsii [Typical Violations of Legislation on the Protection of Minors from Malicious Information]. Uchenye zapiski Krymskogo federalnogo universiteta imeni V.I. Vernadskogo. Juridicheskie nauki, 2017, vol. 3 (69), no. 2, pp. 88-96.

2. Kvest v realnosti «Logovo»v Volgograde ot "Clever» [Quest in Reality "Lair" in Volgograd from "Clever"]. URL: https://volgograd.mir-kvestov.ru/ quests/clever-logovo (accessed 25 June 2020).

3. Postanovlenie suda Oktyabrskogo rayona g. Saratova ot 09.01.2017 № 5-5/2017 [The Ruling of the Oktyabrsky District of Saratov from 9 January 2017 no. 5-5/2017]. Sudebnye i normativnye akty RF [Judicial and Regulatory Acts of the Russian Federation]. URL: https://sudact.ru/regular/doc/ Phu33ItbgXN5 (accessed 25 June 2020).

4. Postanovlenie Tsentralnogo rayonnogo suda g. Volograda ot 15.01.2020 № 5-32/2020 [The Ruling of the Tsentralny District of Volgograd from 15 January 2020 no. 5-32/2020]. Sudebnye i normativnye akty $R F$ [Judicial and Regulatory Acts of the Russian Federation]. URL: https://sudact.ru/regular/doc/ VZxpHg6MZaZf (accessed 25 June 2020).

5. Poyasnitelnaya zapiska $k$ proektu Federalnogo zakona «O zashchite detey ot informatsionnoy produktsii, prichinyayushchey vred $i k h$ zdorovyu, nravstvennomu i dukhovnomu razvitiyu» [Explanatory Note to the Draft Federal Law "On the Protection of Children from Information Products Harmful to Their Health, Moral and Spiritual Development']. URL: https://www.oprf.ru/ru/about/structure/structurenews/ newsitem/13977?PHPSESSID=bqcq 8r4p0882 tdmo6iaonb6eb1 (accessed 5 March 2020).

6. Standart bezopasnosti. Uslugi v kvestindustrii. Rekomendovannye trebovaniya po obespecheniyu 


\section{ВОПРОСЫ ЧАСТНОПРАВОВОГО РЕГУЛИРОВАНИЯ}

bezopasnosti klientov (igrokov) kvestkompanii [Safety Standard. Services in the Quest Industry. Recommended Requirements for Ensuring the Safety of Clients (Players) of the Quest Company]. URL: https:// www. ассоциацияквестовроссии.pф/standartbezopasnosti-v-kvestindust (accessed 29 February 2020).

7. Federalnyy zakon ot 29.12 .2010 no. $436-\mathrm{FZ} « \mathrm{O}$ zashchite detey ot informatsii, prichinyaushchey vred ikh zdorovyu i razvitiyu» [Federal Law “On the Protection of Children from Information that Causes Harm to Their Health and Development" of 29 December 2010 no. 436FZ]. Rossiyskaya gazeta, 2010, 31 Dec. (no. 297).

8. Yushina O.L. Publichnaya biblioteka $v$ obespechenii informatsionno-psikhologicheskoy bezopasnosti chitateley: dis. ... kand. ped. nauk: 05.25.03 [Public Library in Providing Information and Psychological Safety of Readers. Cand. ped. sci. diss. 05.25.03]. Saint Petersburg, 2005. 237 p.

\section{Information About the Author}

Evgeniya A. Serbina, Master Student, Department of Civil and Private International Law, Volgograd State University, Prosp. Universitetsky, 100, 400062 Volgograd, Russian Federation, evg.serbina@yandex.ru, https://orcid.org/0000-0002-2366-4446

\section{Информация об авторе}

Евгения Александровна Сербина, магистрант кафедры гражданского и международного частного права, Волгоградский государственный университет, просп. Университетский, 100, 400062 г. Волгоград, Российская Федерация, evg.serbina@yandex.ru, https://orcid.org/0000-0002-2366-4446 